\title{
EFEITO RESIDUAL DA ADUBAÇÃO DA BATATA SOBRE A PRODUÇÃO DO MILHO-VERDE EM CULTIVO SUCESSIVO'1
}

\author{
ERNANI CLARETE DA SILVA², ADEMAR VIRGOLINO DA SILVA FILHO ${ }^{3}$ \\ e MARCO ANTÔNIO REZENDE ALVARENGA ${ }^{4}$
}

\begin{abstract}
RESUMO - Este trabalho foi realizado em áreas da Fazenda Experimental da Empresa de Pesquisa Agropecuária de Minas Gerais (Epamig), no Município de Três Pontas, MG. O objetivo foi analisar o efeito residual da adubação aplicada no solo, por ocasião do plantio da batata (Solanum tuberosum L.), em subseqüente cultivo de milho-verde (Zea mays L.). A batata, cv. Achat, plantada no espaçamento $0,80 \mathrm{~m} \times 0,40 \mathrm{~m}$, foi adubada nas doses: 0,2 e $4 \mathrm{t} \mathrm{ha}{ }^{-1}$ da fórmula 4-16-8. Após a colheita da batata, o milho-verde, híbrido AG-162, foi semeado no delineamento experimental de blocos casualizados, com quatro repetições, e no esquema de parcelas subdivididas, a saber: nas parcelas, a adubação de plantio da batata, e nas subparcelas, a adubação de plantio do milho-verde (adubado e não adubado). As características analisadas foram: altura média da planta, número de espigas/parcela, produção de espiga com e sem palhas, e concentrações $\mathrm{P}, \mathrm{K}^{+}, \mathrm{Ca}^{2+} \mathrm{e} \mathrm{Mg}^{2+}$. O aumento das doses da adubação mineral da batata aumentou os teores de $\mathrm{P}, \mathrm{K}$ e Ca trocáveis no solo, os quais podem melhorar a produção do milho-verde em cultivo subseqüente.
\end{abstract}

Termos para indexação: Solanum tuberosum, Zea mays, adubos, resíduos, solo, rendimento.

\section{EFFECT OF RESIDUAL FERTILIZER ON GREEN CORN YIELD IN ROTATION WITH POTATO CROP}

\begin{abstract}
This work was carried out at Epamig, Estação Experimental de Três Pontas, MG, Brazil, to evaluate the residual effect of fertilizer applied in potatoes (Solanum tuberosum L.) field on successive green corn (Zea mays L.) production. The potato cv. Achat was grown in plots with three treatments: 0, 2 and $4 \mathrm{t} \mathrm{ha}^{-1}$ of NPK 4-16-8 fertilizer. After potato harvest, hybrid AG-162 Agroceres corn was sown in a randomized block experimental design in split plots, namely: in the plots, the potato fertilizer; and in the subplots, the green corn fertilizer, one with, and one without base fertilizer, and four replications. The following characteristics were evaluated: average length of plant, number of ears per plot, ear production, and soil concentration of $\mathrm{P}, \mathrm{K}^{+}, \mathrm{Ca}^{2+}$ and $\mathrm{Mg}^{2+}$. The increase of mineral fertilization to the potato crop favored a greater nutrients' residual effect, mainly soil exchangeable $\mathrm{P}, \mathrm{K}$ and $\mathrm{Ca}$, which may increase green corn yield when in rotation with potato crop.
\end{abstract}

Index terms: Solanum tuberosum, Zea mays, fertilizers, residues, soil, yields.

\footnotetext{
${ }^{1}$ Aceito para publicação em 19 de abril de 2000.

${ }^{2}$ Eng. Agrôn., Dr., Instituto de Ciências Agrárias, Universidade de Alfenas, Rodovia MG 179, km 0, Caixa Postal 23, CEP 37130-000 Alfenas, MG. E-mail: clarsil@bol.com.br

${ }^{3}$ Eng. Agrôn., M.Sc., Rua Tiradentes, 500, Bela Vista, CEP 53300-00 Petrolina, PE. E-mail: ademar@uol.com.br

${ }^{4}$ Eng. Agrôn., Dr., Prof. Titular, Dep. de Agricultura, UFLA, Caixa Postal 37, CEP 37200-000 Lavras, MG. E-mail: marcoant@ufla.br
}

\section{INTRODUÇÃO}

Em geral, onde a batata (Solanum tuberosum L.) é cultivada intensamente, o uso de fertilizantes em dosagens elevadas aumenta substancialmente o custo de produção da cultura. Neste sentido, Campbell et al. (1991) observaram que os benefícios de uma sucessão ou rotação de cultura adequada incluem uma melhoria na resistência do solo à erosão, bem como melhoria na fertilidade e benefícios agronômicos di- 
retos e indiretos ao produtor. Por outro lado, Holanda (1996) observou que a sucessão de culturas promove, normalmente, maior produção em sistemas convencionais em comparação com os sistemas conservacionistas; entretanto, em condições adversas, como excesso de umidade ou uma deficiente drenagem natural do solo, a tendência é a acentuada queda de produção em sistemas convencionais.

A eficiência dos nutrientes sobre o rendimento das plantas depende de alguns fatores, como, condições climáticas, tipo de solo, capacidade de adsorção dos nutrientes e capacidade de remoção dos nutrientes pelas culturas (Sanchez, 1981). A quantidade de K exportada do solo por ocasião da colheita está diretamente ligada à espécie e ao teor deste nutriente disponível no solo (Ritchey, 1982). Segundo Reis Júnior (1995), a aplicação de doses crescentes de K na cultura da batata aumentou a disponibilidade do nutriente no solo, assim como a quantidade de matéria seca na planta de batata com a adubação potássica residual. Vidigal (1992), analisando o efeito residual de doses de composto orgânico em algumas propriedades físicas do solo e na produção e concentração de nutrientes em plantas de alface após três cultivos sucessivos, observou que houve aumento linear do peso da matéria seca e da matéria fresca, e que o efeito cumulativo das doses do composto orgânico promoveu aumento de $\mathrm{C}$ orgânico, $\mathrm{pH}$, e de teor de $\mathrm{Mg}$ e K trocáveis.

Quanto ao P, a cultura do milho responde, normalmente, às fertilizações fosfatadas de plantio e aos seus efeitos residuais, com significativos aumentos na produção. No sistema de cultivos sucessivos, quando as culturas precedentes são adequadamente adubadas, os efeitos residuais dos fertilizantes fosfatados se fazem notar de forma expressiva. Estudos com solos de alta capacidade de retenção de $\mathrm{P}$ demonstraram que, quando estes foram adequadamente tratados com fertilizantes fosfatados, parte do nutriente permaneceu no solo de forma disponível às plantas por diversos cultivos (Yost et al., 1981). A rotação da cultura do milho-verde, antecedida por outra cultura adubada em grande quantidade, tem-se apresentado como uma excelente opção para o produtor maximizar seus lucros. Contudo, a adubação para produção de milho-verde tem sido pouco estudada, e neste caso, os agricultores adubam como se fosse para produzir grãos, e aproveitam o resíduo de adubações anteriores.

Segundo Filgueira (1982), o milho-verde cultivado após o tomateiro estaqueado tem produzido satisfatoriamente espigas comerciais, apenas com o resíduo das adubações. Esta prática, chamada de cultivo sucessivo, há muito vem sendo utilizada pelos agricultores, os quais, normalmente, não possuem informações suficientes do quanto podem aproveitar do fertilizante remanescente no solo para diminuir os custos de produção.

Objetivou-se, com este trabalho, verificar o efeito residual da adubação aplicada no plantio da batata, em subseqüente cultivo de milho-verde.

\section{MATERIAL E MÉTODOS}

O trabalho foi conduzido durante o ano agrícola 1993/1994, na Fazenda Experimental da Empresa de Pesquisa Agropecuária de Minas Gerais (Epamig), no Município de Três Pontas, MG, localizado a $902 \mathrm{~m}$ de altitude, $45^{0} 30^{\prime}$ de longitude Oeste e $21^{0} 22^{\prime}$ de latitude Sul. O clima é temperado, chuvoso, com inverno seco, segundo aproximação da classificação de Köppen, descrita por Ometto (1981).

O solo, um Latossolo Vermelho-Amarelo, distrófico, de textura argilosa, apresentava as seguintes características: $\mathrm{pH}$ em água $=5,0 ; \mathrm{Al}^{3+}=0,4\left(\mathrm{cmol}_{\mathrm{c}} \mathrm{dm}^{-3}\right)$; $\mathrm{Ca}^{2}=1,11 \quad\left(\mathrm{cmol}_{\mathrm{c}} \mathrm{dm}^{-3}\right) ; \mathrm{Mg}^{2+}=2 \quad\left(\mathrm{cmol}_{\mathrm{c}} \mathrm{dm}^{-3}\right) ;$ $\mathrm{K}^{+}=50,83\left(\mathrm{mg} \mathrm{dm}^{-3}\right) ; \mathrm{P}=3,0\left(\mathrm{mg} \mathrm{dm}^{-3}\right)$; matéria orgânica $=22,8 \mathrm{~g} \mathrm{~kg}^{-1}$; areia $=277 \mathrm{~g} \mathrm{~kg}^{-1} ;$ limo $=181 \mathrm{~g} \mathrm{~kg}^{-1} \mathrm{e}$ argila $=542 \mathrm{~g} \mathrm{~kg}^{-1}$.

A área experimental foi preparada com duas arações e uma gradagem, e, logo após, 25 dias antes da instalação da cultura da batata, recebeu $1,5 \mathrm{t} \mathrm{ha}^{-1}$ de calcário com $54,96 \%$ de $\mathrm{CaO}, 2,42 \%$ de $\mathrm{MgO}$ e PRNT de $104,10 \%$ o qual foi incorporado. Por ocasião da abertura dos sulcos para plantio da batata, cultivar Achat, o solo foi tratado com o equivalente a $1 \mathrm{~kg} \mathrm{ha}^{-1}$ de Aldicarb. Utilizou-se o delineamento de blocos casualizados, com quatro repetições. Cada bloco foi dividido em três parcelas de $38,4 \mathrm{~m}^{2}$ $(6,0 \times 6,4 \mathrm{~m})$, tratadas, respectivamente, com adubações de plantio de 0,2 e $4 \mathrm{t} \mathrm{ha}^{-1}$ do fertilizante formulado 4-16-8 aplicadas no sulco de plantio da batata. A parcela tratada com $0,0 \mathrm{t} \mathrm{ha}^{-1}$ não foi cultivada com batata, recebendo apenas correção com calcário, conforme descrito acima. Como fonte dos nutrientes, utilizou-se nitrocálcio, superfosfato simples e cloreto de potássio. A batata foi plantada no espaçamento $0,80 \mathrm{~m}$ entre fileiras e $0,40 \mathrm{~m}$ entre plantas, e as parcelas, formadas por oito fileiras de $6 \mathrm{~m}$ de comprimento. Simultaneamente à adubação de 
plantio da batata efetuou-se adubação complementar com o equivalente a $20 \mathrm{~kg} \mathrm{ha}^{-1}$ de bórax e $100 \mathrm{~kg} \mathrm{ha}^{-1}$ de sulfato de $\mathrm{Mg}$ aplicados nos sulcos de plantio. Trinta e oito dias após a emergência das plantas, por ocasião da amontoa, realizou-se adubação de cobertura na base $80 \mathrm{~kg} \mathrm{ha}^{-1}$ de $\mathrm{N}$, na forma de nitrocálcio, acompanhando a linha de plantio. Os tratamentos fitossanitários foram realizados de acordo com o recomendado para a cultura.

Após a colheita da batata, os restos culturais foram incorporados, e procedeu-se a nova amostragem de solo, para análise química, 120 dias após a adubação de plantio. Posteriormente, realizou-se nova abertura de sulcos, para plantio do milho-verde, caracterizando o plantio sucessivo. O milho-verde, híbrido AG-162, foi semeado no delineamento experimental de blocos casualizados, com quatro repetições e no esquema de parcelas subdivididas, tendo nas parcelas a adubação de plantio da batata $\left(0,2\right.$ e $4 \mathrm{t} \mathrm{ha}^{-1}$ de 4-16-8), e nas subparcelas, a adubação de plantio do milho-verde (adubado e não-adubado), totalizando seis tratamentos.

O plantio do milho-verde foi realizado no espaçamento de $0,80 \mathrm{~m}$ entre fileiras, com quatro plantas por metro linear, constituindo apenas um plantio sucessivo. Cada subparcela foi formada por quatro fileiras, nas quais as duas centrais, excluindo-se meio metro de cada extremidade, totalizaram quarenta plantas da área útil com $8 \mathrm{~m}^{2}$.

A adubação utilizada para a cultura do milho foi feita com base nas recomendações da Comissão de Fertilidade do Estado de Minas Gerais (1989), para produção de grãos em solos com fertilidade baixa, consistindo, no plantio, de $20 \mathrm{~kg} \mathrm{ha}^{-1}$ de $\mathrm{N}$ (nitrocálcio), $70 \mathrm{~kg} \mathrm{ha}^{-1}$ de $\mathrm{P}_{2} \mathrm{O}_{5}$ (superfosfato simples) e $60 \mathrm{~kg} \mathrm{ha}^{-1} \mathrm{de}_{2} \mathrm{O}$ (cloreto de $\mathrm{K}$ ). Realizou-se adubação em cobertura com $40 \mathrm{~kg} \mathrm{ha}^{-1}$ de $\mathrm{N}$ na forma de sulfato de amônio, 35 dias após a emergência, em todos os tratamentos. Os demais tratos culturais e fitossanitários foram feitos de acordo com o recomendado para a cultura.

Procedeu-se a duas colheita de milho, aos 99 e aos 106 dias do plantio, e as espigas foram coletadas no estádio de grãos leitosos para grãos pastosos, onde foram avaliadas as características: altura média das plantas, número de espigas/parcela e produção de espigas com palha e sem palhas. Aos 120 dias após a adubação de plantio do milho, procedeu-se a nova análise química do solo no qual os teores de $\mathrm{P}, \mathrm{K}^{+} \mathrm{Ca}^{2+}$ e $\mathrm{Mg}^{2+}$ foram quantificados. Para a avaliação dos teores de $\mathrm{P}$ e $\mathrm{K}^{+}$, utilizou-se extrator Mehlich-1, e para $\mathrm{Ca}^{2+}{\mathrm{e} \mathrm{Mg}^{2+} \text {, extrator } \mathrm{KCl} \mathrm{mol} \mathrm{L}}^{-1}$.

\section{RESULTADOS E DISCUSSÃO}

A análise química do solo antes e após o cultivo da batata e após o cultivo do milho, mostrou aumento significativo da disponibilidade de Ca e Mg após o cultivo da batata, principalmente na dose $4 \mathrm{t} \mathrm{ha}^{-1}$ (Tabela 1). A calagem do solo com a incorporação uniforme desses nutrientes e das fontes de $\mathrm{N}$ e $\mathrm{P}$ utilizadas, respectivamente, o nitrocálcio e o superfosfato simples, explicam esse resultado; no que se refere ao Ca, resultados semelhantes foram obtidos por Scholes et al. (1978).

Maiores concentrações residuais de $\mathrm{P}$ e $\mathrm{K}$ solúveis foram observadas nas parcelas que receberam adubação, e a dosagem equivalente a $4 \mathrm{t} \mathrm{ha}^{-1}$ da fórmula 4-16-8 proporcionou os maiores teores residuais de $\mathrm{P}$ e $\mathrm{K}^{+}$no solo. Ressalta-se ainda um maior acréscimo do efeito residual do $\mathrm{P}$, em relação ao $\mathrm{K}$, quando se elevou a dose de 2 para $4 \mathrm{t} \mathrm{ha}^{-1}$ de fertilizante, provavelmente causado pela perda de K por lixiviação, conforme comprovou Ritchey (1982); segundo Yost et al. (1981), isto não acontece com o $\mathrm{P}$, embora fatores como a absorção e exportação pela cultura possam também estar influindo.

Pelas análises realizadas logo após a colheita do milho-verde, verificou-se efeito residual das adubações anteriores, o qual variou em razão das adubações no plantio da batata e/ou do milho-verde

TABELA 1. Teores médios de cálcio, magnésio, potássio e fósforo no solo antes e depois do cultivo da batata e após o cultivo do milho. Três Pontas, MG, 1994'.

\begin{tabular}{lcccc}
\hline $\begin{array}{c}\text { Fórmula 4-16-8 } \\
\left(\mathrm{t} \mathrm{ha}^{-1}\right)\end{array}$ & $\mathrm{Ca}^{2+}$ & $\mathrm{Mg}^{2+}$ & $\mathrm{K}^{+}$ & $\mathrm{P}$ \\
\multicolumn{5}{c}{ Antes do cultivo da batata } \\
\hline \multicolumn{5}{c}{ Após o cultivo da batata } \\
\hline 0 & 1,11 & 0,19 & 0,13 & 3,00 \\
2 & $1,85 \mathrm{~b}$ & $0,31 \mathrm{~b}$ & $0,12 \mathrm{c}$ & $4,88 \mathrm{c}$ \\
4 & $2,01 \mathrm{ab}$ & $0,34 \mathrm{ab}$ & $0,24 \mathrm{~b}$ & $16,88 \mathrm{~b}$ \\
\hline DMS & $2,26 \mathrm{a}$ & $0,35 \mathrm{a}$ & $0,29 \mathrm{a}$ & $27,25 \mathrm{a}$ \\
CV $(\%)$ & 0,27 & 0,03 & 0,04 & 6,01 \\
\hline \multicolumn{5}{c}{ Após o cultivo do milho } \\
0 & 10,30 & 7,50 & 13,13 & 28,15 \\
2 & $2,07 \mathrm{a}$ & $0,12 \mathrm{a}$ & $0,08 \mathrm{~b}$ & $9,37 \mathrm{~b}$ \\
4 & $2,21 \mathrm{a}$ & $0,14 \mathrm{a}$ & $0,15 \mathrm{a}$ & $18,88 \mathrm{ab}$ \\
\hline DMS & $2,37 \mathrm{a}$ & $0,14 \mathrm{a}$ & $0,15 \mathrm{a}$ & $30,75 \mathrm{a}$ \\
CV $(\%)$ & 0,64 & 0,04 & 0,04 & 15,48 \\
\hline
\end{tabular}

${ }^{1}$ As médias seguidas pela mesma letra na coluna não diferem entre si pelo teste de Tukey a $5 \%$ de probabilidade.

${ }^{2}$ A fórmula 4-16-8 foi aplicada somente por ocasião do cultivo da batata. 
(Tabelas 1 e 2). Assim, os teores de P e K disponíveis variaram, em razão do efeito residual da batata, enquanto a adubação do milho influenciou significativamente os teores de $\mathrm{P}, \mathrm{K}$ e Ca disponíveis no solo (Tabela 2). Os efeitos residuais dos nutrientes $\mathrm{Pe} \mathrm{Ca}$ proporcionados pela adubação da batata persistiram também após o cultivo do milho-verde, o que não aconteceu com o K, que apresentou teor semelhante ao teor inicial (Tabela 1). Observou-se, ainda, uma equivalência nos níveis de $\mathrm{K}$ residual do solo nas parcelas adubadas anteriormente, com as doses de 2 e $4 \mathrm{t} \mathrm{ha}^{-1}$, o que sugere uma perda do nutriente por lixiviação, quando aplicado no sulco em doses maiores do que $2 \mathrm{t} \mathrm{ha}^{-1}$ da fórmula 4-16-8 (160 $\mathrm{kg} \mathrm{ha}^{-1}$

TABELA 2. Valores médios de $\mathrm{P}, \mathrm{K}^{+}, \mathrm{Ca}^{2+}{\mathrm{e} \mathrm{Mg}^{2+} \mathrm{em}}^{-}$ amostras de solo, após a colheita do milho, em razão dos níveis de adubação residual da batata e da presença ou ausência da adubação de plantio do milho-verde. Três Pontas, MG, 1994'.

\begin{tabular}{|c|c|c|c|c|}
\hline $\begin{array}{l}\text { Adubação do } \\
\text { milho-verde }\end{array}$ & $\begin{array}{c}\mathrm{P} \\
\left(\mathrm{mg} \mathrm{dm}^{-3}\right)\end{array}$ & $\mathrm{K}^{+}$ & $\begin{array}{c}\mathrm{Ca}^{2+} \\
\mathrm{cmol}_{\mathrm{c}} \mathrm{dm}^{-3}\end{array}$ & ${ }^{3} \mathrm{Mg}^{2+}$ \\
\hline Adubado & $29,00 \mathrm{a}$ & $0,13 a$ & $2,44 a$ & $0,13 \mathrm{a}$ \\
\hline Não-adubado & $10,33 b$ & $0,11 \mathrm{~b}$ & $1,99 \mathrm{~b}$ & $0,14 \mathrm{a}$ \\
\hline DMS & 7,61 & 0,01 & 0,37 & 0,03 \\
\hline $\mathrm{CV}(\%)$ & 41,90 & 11,55 & 18,19 & 23,89 \\
\hline
\end{tabular}

1 As médias seguidas pela mesma letra na coluna não diferem entre si pelo teste de Tukey a $5 \%$ de probabilidade. de $\mathrm{K}_{2} \mathrm{O}$ ), adubado ou não, no plantio do milho. Quanto ao efeito residual do $\mathrm{P}$ disponível no solo, a dose de $4 \mathrm{t} \mathrm{ha}^{-1}$ da fórmula de adubação da batata promoveu um incremento de 10,37 e $22,37 \mathrm{mg} \mathrm{dm}^{-3}$ de $\mathrm{P}$ no solo, relativamente às dosagens de duas e zero t ha ${ }^{-1}$, respectivamente (Tabela 1). Este fato, aliado à ausência de interação com a adubação do milho, demonstra o efeito direto dos teores crescentes do nutriente residual no solo. Houve efeito positivo da adubação realizada no plantio do milho-verde nos teores de $\mathrm{P}$ disponível, do $\mathrm{K}$ e Ca trocáveis no solo, o que evidencia o enriquecimento do solo, no decorrer da rotação das culturas, bem como o efeito residual dos nutrientes no solo.

Não houve interação significativa dos dois fatores estudados (adubação da batata $\mathrm{x}$ adubação de plantio do milho-verde) sobre as características avaliadas, como: altura média das plantas, número e produção de espigas comerciais com e sem palha (Tabela 3). Entretanto, os fatores, quando analisados isoladamente, revelaram que as respectivas características sofreram acréscimos, à medida que se elevaram as doses da adubação da batata (Tabela 4). Os dados de resíduos de adubação analisados anteriormente talvez possam explicar os respectivos resultados, já que respostas semelhantes foram obtidas por Yost et al. (1981) ao estudarem o efeito residual de P e K na produção de milho. Por outro lado, essas mesmas características do milho-verde também foram significativamente superiores nas parcelas onde foi

TABELA 3. Análise de variância dos dados referentes a altura média de plantas, número de espigas comerciais e não-comerciais, produção de espigas comerciais com palha, produção de espigas comerciais sem palha e produção de espigas não comerciais sem palha. Três Pontas, MG, 1994.

\begin{tabular}{|c|c|c|c|c|c|c|c|}
\hline \multirow[t]{3}{*}{ Fonte de variação } & \multirow[t]{3}{*}{ GL } & \multirow{3}{*}{$\begin{array}{l}\text { Altura média } \\
\text { de plantas } \\
(\mathrm{cm})\end{array}$} & \multicolumn{2}{|c|}{ Número de espigas $^{1}$} & \multicolumn{2}{|c|}{ Espigas comerciais } & \multirow{3}{*}{$\begin{array}{l}\text { Espigas não- } \\
\text { comerciais sem } \\
\text { palha }\end{array}$} \\
\hline & & & Comerciais & $\begin{array}{c}\text { Não- } \\
\text { comerciais }\end{array}$ & Com palha & Sem palha & \\
\hline & & & & & -------- & (1) & \\
\hline $\begin{array}{l}\text { Adubação da } \\
\text { batata (A) }\end{array}$ & 2 & $33753,35 * *$ & $1,1659 * *$ & 0,0299 & $27018864,00 *$ & $12752695,00^{*}$ & 52767,12 \\
\hline Blocos & 3 & 234,10 & 0,1321 & 0,2138 & 2514219,25 & 847017,56 & 25133,94 \\
\hline Erro (a) & 6 & 189,12 & 0,1954 & 0,0454 & 3184291,00 & 1710322,62 & 72384,39 \\
\hline $\begin{array}{l}\text { Adubação do } \\
\text { milho (B) }\end{array}$ & 1 & $3937,02 * *$ & $3,5465 * *$ & 0,0191 & $95996000,00 * *$ & $37783032,00 * *$ & 4108,16 \\
\hline$A \times B$ & 2 & $168,14^{\mathrm{ns}}$ & $0,6363^{\mathrm{ns}}$ & $0,2421^{\mathrm{ns}}$ & $5617950,00^{\mathrm{ns}}$ & $4373680,50^{\mathrm{ns}}$ & $139698,79^{\mathrm{ns}}$ \\
\hline Erro (b) & 9 & 237,65 & 0,2160 & 0,1759 & 2287344,75 & 1735413,00 & 199431,17 \\
\hline $\mathrm{CV}_{1}(\%)$ & & 6,41 & 7,81 & 5,76 & 13,54 & 17,94 & 25,46 \\
\hline $\mathrm{CV}_{2}(\%)$ & & 7,19 & 8,21 & 11,35 & 11,48 & 18,08 & 42,26 \\
\hline
\end{tabular}

${ }^{1}$ Dados transformados para $\sqrt{\mathrm{x}}$.

ns, * e ** Não-significativo e significativo a $5 \%$ e $1 \%$ de probabilidade, respectivamente, pelo teste $\mathrm{F}$. 
TABELA 4. Valores médios da produção dos dados referentes à produção e componentes da produção do milho-verde, em razão do resíduo da adubação da batata e da adubação no plantio do milho-verde. Três Pontas, MG, 1994'.

\begin{tabular}{lcccc}
\hline $\begin{array}{c}\text { Adubação da batata } \\
\left(\mathrm{t} \mathrm{ha}^{-1}\right)\end{array}$ & $\begin{array}{c}\text { Altura média } \\
\text { das plantas }(\mathrm{cm})\end{array}$ & $\begin{array}{c}\mathrm{N}^{\mathbf{0}} \text { de espigas } \\
\text { comerciais/parcela }\end{array}$ & $\begin{array}{c}\text { Produção de espigas } \\
\text { comerciais com palha } \\
\left(\mathrm{kg} \mathrm{ha}^{-1}\right)\end{array}$ & $\begin{array}{c}\text { Espigas comercias sem } \\
\text { palha }\left(\mathrm{kg} \mathrm{ha}^{-1}\right)\end{array}$ \\
\hline \multicolumn{1}{c}{0} & $193,13 \mathrm{~b}$ & $28,00 \mathrm{c}$ & $11211,00 \mathrm{~b}$ & $6000,00 \mathrm{~b}$ \\
2 & $213,69 \mathrm{~b}$ & $32,75 \mathrm{~b}$ & $13469,00 \mathrm{ab}$ & $7341,00 \mathrm{ab}$ \\
4 & $234,43 \mathrm{a}$ & $36,63 \mathrm{a}$ & $14852,00 \mathrm{a}$ & $8524,00 \mathrm{a}$ \\
\hline DMS & 21,10 & 0,68 & 2738,11 & 2006,71 \\
CV $(\%)$ & 6,41 & 7,81 & 13,54 & 17,94 \\
\hline Adubação de plantio & & & & \\
\hline Adubado & $227,22 \mathrm{a}$ & $36,83 \mathrm{a}$ & $15.177,00 \mathrm{a}$ & $8.543,00 \mathrm{a}$ \\
Não-adubado & $201,61 \mathrm{~b}$ & $28,08 \mathrm{~b}$ & $11.177,00 \mathrm{~b}$ & $6.033,00 \mathrm{~b}$ \\
\hline DMS & 14,24 & 0,43 & 1397,09 & 1216,92 \\
CV $(\%)$ & 7,19 & 8,21 & 11,48 & 18,08 \\
\hline
\end{tabular}

1 As médias seguidas pela mesma letra na coluna não diferem entre si pelo teste de Tukey a $5 \%$ de probabilidade.

2 Calculada com dados transformados para $\sqrt{\mathrm{x}}$.

aplicada adubação de plantio, o que indica haver respostas independentemente de haver ou não resíduo da adubação anterior.

\section{CONCLUSÃO}

Em áreas cultivadas com batata persistem resíduos de fertilizantes no solo pós-cultivo, os quais influenciam positivamente as características químicas desse solo, e podem também melhorar o rendimento do milho-verde quando cultivado em sucessão.

\section{REFERÊNCIAS}

CAMPBELL, C.A.; BIEDERBECK, V.O.; ZENITNER, R.P.; LAFOND, G.P. Effect of crop rotations and cultural practices on soil organic matter, microbial biomass and respirations in a thin back chernozem. Canadian Journal of Soil Science, Ottawa, v.71, n.3, p.363-376, Aug. 1991.

COMISSÃO DE FERTILIDADE DO ESTADO DE MINAS GERAIS (Lavras, MG). Recomendações para o uso de corretivos e fertilizantes em Minas Gerais: $4^{\mathrm{a}}$ aproximação. Lavras, 1989. 176p.

FILGUEIRA, F.A.R. Manual de olericultura. 2.ed. São Paulo : Ceres, 1982. v.2.

HOLANDA, F.S.R. Efeito de sistemas de preparo de solo e sucessão de culturas: 1. Estratificação de fósforo, potássio, pH e matéria orgânica. 2. Absorção de $\mathrm{P}$ e
K pela cultura do milho (Zea mays L.). Lavras : UFLA, 1996. 86p. Tese de Doutorado.

OMETTO, J.C. Bioclimatologia vegetal. São Paulo : Ceres, 1981. 425p.

REIS JÚNIOR, R. dos A. Produção, qualidade de tubérculos e teores de potássio no solo e no pecíolo de batateira em respostas à adubação potássica. Viçosa : UFV, 1995. 108p. Dissertação de Mestrado.

RITCHEY, K.D. O potássio nos Oxissolos e Ultissolos dos trópicos úmidos. Piracicaba : Instituto Internacional da Potassa, 1982. 69p. (Boletim Técnico, 7).

SANCHEZ, P.A. Suelos del trópico: características y manejo. San José : IICA, 1981. p.491-542.

SCHOLES, D.; ANGHINONI, I.; STAMMEL, J.G. Efeito residual da aplicação de doses de calcário na produção de forrageiras tropicais e nas propriedades químicas de um solo laterítico Bruno-Amarelo distrófico. Agronomia Sulriograndense, Porto Alegre, v.14, n.1, p.135-142, 1978.

VIDIGAL, S.M. Efeito residual da adubação orgânica no terceiro cultivo sucessivo de alface (Lactuca sativa L.). Viçosa : UFV, 1992. 73p. Dissertação de Mestrado.

YOST, R.S.; KAMPRATH, E.J.; NADERMAN, G.C.; LOBATO, E. Residual effects of phosphorus applications on a high phosphorus adsorbing oxisol of Central Brazil. Soil Science Society of America. Proceedings, Madison, v.45, n.3, p.540-543, 1981. 